\title{
KdpFABC Reconstituted in Escherichia coli Lipid Vesicles: Substrate Dependence of the Transport Rate
}

\author{
Bojana Damnjanovic ${ }^{\#}$ and Hans-Jürgen Apell* \\ Department of Biology and Konstanz Research School Chemical Biology, University of Konstanz, 78464 Konstanz, Germany
}

ABSTRACT: KdpFABC complexes were reconstituted in Escherichia coli lipid vesicles, and ion pumping was activated by addition of ATP to the external medium which corresponds to the cytoplasm under physiological conditions. ATP driven potassium extrusion was studied in the presence of various substrates potentially influencing transport rate. The pump current was detected as a decrease of the membrane potential by the voltage sensitive dye $\mathrm{DiSC}_{3}(5)$. The results indicate that high cytoplasmic $\mathrm{K}^{+}$concentrations have an inhibitory effect on the KdpFABC complex. The pump current decreased to $\sim 25 \%$ of the maximal value at $140 \mathrm{mM} \mathrm{K}^{+}$and minimal $\mathrm{Mg}^{2+}$ concentrations. This effect could be counteracted with increased $\mathrm{Mg}^{2+}$ concentrations on the cytoplasmic side. This observation may be explained by the Gouy-Chapman effect of two $\mathrm{Mg}^{2+}$ ions probably bound with a $K_{1 / 2}$ of $0.8 \mathrm{mM}$ close to the entrance of the access channel to the binding sites. This

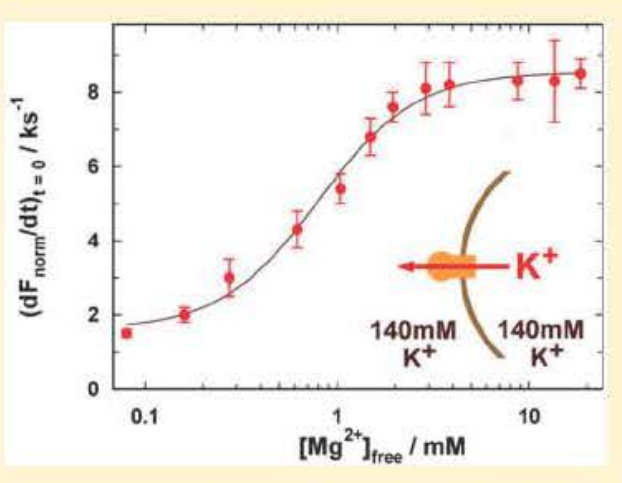
factor ensures that under physiological conditions the rate limiting effect of $\mathrm{K}^{+}$release is significantly reduced. Also both ADP and inorganic phosphate are able to reduce the turnover rate of the pump by reversing the phosphorylation step $\left(K_{1}\right.$ of $\left.151 \mu \mathrm{M}\right)$ and the dephosphorylation step ( $K_{1}$ of $268 \mu \mathrm{M}$ ), respectively. In the case of the DDM solubilized KdpFABC complex, activation energy under turnover conditions was previously found to be $55 \mathrm{~kJ} / \mathrm{mol}$, and the $o$ vanadate inhibition constant is shown here to be $\sim 1 \mu \mathrm{M}$, which is in agreement with values reported for other P type ATPases. In the case of the reconstituted enzyme, however, significant differences were observed that have to be assigned to effects of the lipid bilayer environment. The activation energy was increased by a factor of 2 , whereas the inhibition by $o$ vanadate became reduced in a way that only $\sim 66 \%$ of the enzyme could be inhibited and the inhibition constant was increased to a value of $\sim 60 \mu \mathrm{M}$.

$\mathrm{K}$ dpFABC complex of Escherichia coli, a member of the P type ATPase family, is an emergency and high affinity potassium uptake system, only expressed under $\mathrm{K}^{+}$limiting conditions. In contrast to other members of the P type ATPase family that consist of a catalytic subunit performing both ion transport and ATP hydrolysis, the KdpFABC complex has a unique structure-function relationship of four different subunits. The largest subunit, $\mathrm{KdpB}$, represents the ATP hydrolysis catalytic subunit ${ }^{1}$ and is dassified as type la $\mathrm{P}$ type ATPase. ${ }^{2}$ The KdpA subunit, structurally similar to the KcsA like $\mathrm{K}^{+}$channels, is proposed to mediate ion binding and transport. ${ }^{3} \mathrm{KdpC}$ acts as a molecular chaperone and is involved in the ATP binding process, ${ }^{4}$ whereas the smallest subunit, $\mathrm{KdpF}$, has the role of a functional lipid that is responsible for the structural integrity of the complex and the stability of the dimeric, functional form. ${ }^{5}$

According to the recently proposed Post Albers cycle for the $\mathrm{KdpFABC}$ complex, binding and transport of $2 \mathrm{~K}^{+}$occur in the dephosphorylation half cycle in correspondence with the "classical" schemes accepted for the $\mathrm{Na}, \mathrm{K}$ ATPase and $\mathrm{H}, \mathrm{K}$ ATPase. ${ }^{6}$ The presence of $3 \mathrm{H}^{+}$bound inside the membrane domain of the $\mathrm{KdpFABC}$ is a prerequisite for the ATP driven half cycle, although they are not translocated but remain bound throughout the whole pump cycle. Apart from electrogenic binding to these "functional" sites, protons can act in the transport sites as weak congener of $\mathrm{K}^{+}$in the absence of $\mathrm{K}^{+}$, or as noncompetitive inhibitor affecting the enzyme activity and/ or the coupling between $\mathrm{KdpA}$ and $\mathrm{KdpB}$ in an unspecific but $\mathrm{pH}$ dependent manner.

It has been reported previously that enzyme activity and $\mathrm{K}^{+}$ transport are dependent on $\mathrm{K}^{+}$concentration, and it has been shown that the $\mathrm{KdpFABC}$ is capable of transporting other monovalent cations, although to a lesser extent. ${ }^{7,8}$ Furthermore, influence of $\mathrm{pH}$ on $\mathrm{K}^{+}$transport and possible proton transport in the absence of $\mathrm{K}^{+}$were investigated with reconstituted KdpFABC complex in E. coli lipid vesicles. ${ }^{9}$ The rather small pump current was found to be maximal in the $\mathrm{pH}$ range of 7.37.4, whereas at lower and higher $\mathrm{pH}$ the pump current decreased significantly. At low $\mathrm{pH}$ values, back binding of protons reduces the electrogenic pump activity, whereas at high $\mathrm{pH}$ the lack of protons in the functional sites inhibits the pump current. ${ }^{6}$ Furthermore, the detected (net) proton transport in the absence of $\mathrm{K}^{+}$was found to be in the opposite direction to the physiologically relevant $\mathrm{K}^{+}$transport. ${ }^{9}$

$\mathrm{Mg}^{2+}$ is required as an essential cofactor for the phosphorylation of the P type ATPases. In the case of the $\mathrm{Na}, \mathrm{K}$ ATPase, it was reported that it can be replaced by other 
divalent cations, e.g., $\mathrm{Ca}^{2+}$, although none of these was as effective as $\mathrm{Mg}^{2+}$. ${ }^{10}$

KdpFABC transports $\mathrm{K}^{+}$ions against their electrochemical potential gradient across the membrane utilizing the energy released during ATP hydrolysis. Products of the ATP hydrolysis, $\mathrm{ADP}$ and inorganic phosphate, $\mathrm{P}_{\mathrm{i}}$, are proposed to affect the KdpFABC pumping process. Besides the direct competition between ATP and ADP at their binding site, the presence of $\mathrm{ADP}$ in the medium may also reverse the phosphorylation step, $\mathrm{E}_{1} \mathrm{ATP} \leftrightarrow \mathrm{E}_{1} \mathrm{P}+\mathrm{ADP}$, thus decreasing the overall turnover rate of the $\mathrm{KdpFABC}$. In the same manner, inorganic phosphate may decelerate the turnover rate by shifting the dephosphorylation equilibrium toward the phosphorylated state, $\mathrm{P} \mathrm{E}_{2} \mathrm{~K}_{2} \leftrightarrow \mathrm{E}_{2}\left(\mathrm{~K}_{2}\right)+\mathrm{P}_{\mathrm{i}}$.

The phosphate analogue $o$ vanadate is a well known specific inhibitor of all $P$ type ATPases. Vanadate binds to the $E_{2}$ state of the enzyme, mimicking the phosphorylated $\mathrm{E}_{2}$ transition state. Among the first suggestions that $\mathrm{KdpFABC}$ is indeed a member of the P type ATPases was the observed inhibition of enzymatic activity by micromolar concentrations of $o$ vanadate. ${ }^{11,12}$

A fluorescence technique employing a potential sensitive dye $\mathrm{DiSC}_{3}(5)$ was applied to investigate the electrogenicity of the $\mathrm{K}^{+}$transport by the KdpFABC reconstituted in lipid vesicles. It was already shown that ATP induced pumping of $\mathrm{K}^{+}$by the inside out oriented pumps is an electrogenic process. ${ }^{9,13}$ The detected fluorescence decrease of the membrane potential indicator, $\mathrm{DiSC}_{3}(5)$, corresponds to the inside negative potential as a result of extrusion from the vesicles of net positive charge. In such experiments, the pump current of the reconstituted $\mathrm{KdpFABC}$ is activated by extravesicular (equiv alent to cytoplasm) ATP, $\mathrm{Mg}^{2+}$, and intravesicular (equivalent to periplasmic) $\mathrm{K}^{+}$.

Here using $\operatorname{DiSC}_{3}(5)$, the pump activity of the reconstituted inside out $\mathrm{KdpFABC}$ in E. coli lipid vesicles was investigated as a function of the composition of the extravesicular (cytoplasmic) medium. In the first part, the effects of cytoplasmic $\mathrm{K}^{+}$and $\mathrm{Mg}^{2+}$ on the pump current are presented, followed by the dependences on $\mathrm{ADP}$ and inorganic phosphate, which are the products of ATP hydrolysis. The concentration changes of ATP, ADP, and inorganic phosphate during the experiments are considered to be negligible due to the large external medium volume. In the second part, the specific inhibition of enzyme activity, and therefore also of the transport, by $o$ vanadate was tested with both the $\beta$ DDM solubilized complex and reconstituted into E. coli vesicles. To study the energetics of the enzyme and transport activity of $\mathrm{KdpFABC}$, their temperature dependence was investigated, providing the corresponding activation energies.

\section{MATERIALS AND METHODS}

Materials. Total lipid extract from E. coli was purchased from Avanti Polar Lipids. The fluorescent dye $\mathrm{DiSC}_{3}(5)$ was ordered from Sigma Aldrich. $\mathrm{Na}_{2} \mathrm{ATP}(\geq 99 \%)$ and valinomycin were obtained from Boehringer Mannheim. $\beta$ DDM was purchased from Anatrace (Maumee, OH). BioBeads SM 2 were obtained from Biorad. MgATP $(\geq 95 \%)$ and all other reagents were purchased from Merck or Sigma Aldrich at the highest quality available.

Purification of the KdpFABC complex. The $\mathrm{C}$ terminally $\mathrm{His}_{14}$ tagged KdpFABC complex was expressed in E. coli as described previously. ${ }^{9}$ The enzyme complexes were solubilized in buffer containing $1 \%(\mathrm{w} / \mathrm{v}) \beta \mathrm{DDM}$ for $1 \mathrm{~h}$ on ice.
Solubilized complexes were collected by centrifugation at $200000 \mathrm{~g}$ at $4{ }^{\circ} \mathrm{C}$ for $1 \mathrm{~h}$, and the supernatant was applied to a 5 $\mathrm{mL}$ HisTrap column (GE Healthcare), pre equilibrated with 50 $\mathrm{mM}$ Tris $\mathrm{HCl}, 20 \mathrm{mM} \mathrm{MgCl} 2,10 \%$ (v/v) glycerol, $150 \mathrm{mM}$ $\mathrm{NaCl}, 10 \mathrm{mM}$ imidazole, $0.5 \mathrm{mM}$ PMSF ( $\mathrm{pH} 7.5$ ) and $0.2 \%$ (w/v) $\beta$ DDM. The column was connected to a FPLC system (Amersham, Biotech) and washed with the same buffer containing $20 \mathrm{mM}$ imidazole at flow rate $0.5 \mathrm{~mL} / \mathrm{min}$. Thereafter, the enzyme was eluted with buffer containing 130 $\mathrm{mM}$ imidazole. Samples of the protein containing fractions were analyzed on a $12.5 \%$ SDS PAGE gel. Afterward, fractions containing the same amount of all subunits were collected and concentrated (Vivaspin, 650.000 MWCO).

Reconstitution of the KdpFABC Complex in Lipid Vesicles. An appropriate amount of E. coli lipids dissolved in chloroform was vacuum dried under rotation in a glass flask, and the obtained thin lipid film was solubilized with dialysis buffer containing $25 \mathrm{mM}$ imidazole, $1 \mathrm{mM}$ EDTA, $5 \mathrm{mM}$ $\mathrm{MgSO}_{4}, 70 \mathrm{mM} \mathrm{K}_{2} \mathrm{SO}_{4}$ at $\mathrm{pH} 7.2,2 \% \beta \mathrm{DDM}$, and $2 \% \mathrm{C}_{12} \mathrm{E}_{8}$ to the final lipid concentration of $10 \mathrm{mg} / \mathrm{mL}$. Sulfate was chosen because it has a significantly lower membrane permeability than chloride. The lipid/detergent mixture was sonicated under nitrogen atmosphere and kept at room temperature until a clear solution was obtained. Equal volumes of $\beta$ DDM solubilized $\mathrm{KdpFABC}$ and E. coli lipid solution were mixed at a protein/ lipid ratio of 1:5 (w/w). Removal of detergent was accomplished by adding 30\% (w/v) Bio Beads followed by constant shaking overnight at $4{ }^{\circ} \mathrm{C}$. Finally, the vesicles were separated from the beads using capillary tips and stored for $3 \mathrm{~h}$ on ice before used in fluorescence experiments. Size distribution of the vesicles was determined by dynamic light scattering using a DLS Viscotek 802 spectrometer. The vesicle diameter was found to be $117 \pm 21 \mathrm{~nm}$ (SD).

Determination of Protein Concentration and ATPase Activity. The concentration of detergent solubilized protein was determined by the Lowry assay. The ATPase activity was determined at $37^{\circ} \mathrm{C}$ using the malachite green assay., ${ }^{9,14}$ The enzyme activity of the $\beta$ DDM solubilized KdpFABC complex was typically $\sim 0.53 \mu \mathrm{mol}$ of $\mathrm{P}_{\mathrm{i}} \mathrm{mg}^{-1} \mathrm{~min}^{-1}$ in the presence of saturating $\mathrm{KCl}$ and ATP concentrations. The ATPase activity of $\mathrm{KdpFABC}$ reconstituted in vesicles was determined in the absence of detergents, which means that only the activity of the inside out oriented $\mathrm{KdpFABC}$ fraction complexes was detected due to the membrane impermeability to ATP. The ATPase activity was found to be $\sim 0.28 \mu \mathrm{mol}$ of $\mathrm{P}_{\mathrm{i}} \mathrm{mg}^{-1} \mathrm{~min}^{-1}$ in the presence of $70 \mathrm{mM} \mathrm{K}_{2} \mathrm{SO}_{4}$ and $5 \mathrm{mM} \mathrm{MgSO}_{4}(\mathrm{pH} \mathrm{7.2)}$. The observation that the enzyme activity of the inside out oriented ATPases is about half of the activity of the solubilized enzyme indicates that the pumps are reconstituted equally in both orientation. The amount of protein needed for a single measurement was $\sim 1 \mu \mathrm{g}$.

$\mathrm{DiSC}_{3}(5)$ Fluorescence Experiments. The positively charged fluorescent dye $\operatorname{DiSC}_{3}(5)$ has been introduced as an indicator of inside negative membrane potentials in vesicles, and it has been successfully used to detect the electrogenic pump activity of the reconstituted KdpFABC complex. ${ }^{9,13}$ Only the inside out oriented ion pumps are activated by the addition of ATP to the external medium, and the outward oriented transport of $\mathrm{K}^{+}$generates an inside negative electric potential. The only anion was sulfate to minimize leak current through the vesicle membrane. The intravesicular $\mathrm{K}^{+}$concentration was $140 \mathrm{mM}$ in all experiments. To perform an experiment, $1 \mathrm{~mL}$ of standard buffer containing $25 \mathrm{mM}$ imidazole, $1 \mathrm{mM}$ EDTA, 5 
$\mathrm{mM} \mathrm{MgSO}_{4}$ ( $\mathrm{pH}$ 7.2), and different concentrations of $\mathrm{K}^{+}$, $\mathrm{Mg}^{2+}, \mathrm{ADP}$, and inorganic phosphate, were thermally equilibrated in a fluorescence cuvette in a PerkinElmer LS 50B luminescence spectrometer. Fluorescence was excited at $650 \mathrm{~nm}$ (slit $5 \mathrm{~nm}$ ), and the emission was detected at $675 \mathrm{~nm}$ (slit $5 \mathrm{~nm}$ ). $300 \mathrm{nM} \mathrm{DiSC}(5)$ and an aliquot of the vesicle suspension containing about $80 \mu \mathrm{g} / \mathrm{mL}$ lipids were added. When a steady state fluorescence level was obtained, $2.5 \mathrm{mM}$ ATP $(\mathrm{pH} \sim 7)$ were added to trigger the pump activity. The pump activity was reflected in a fluorescence decrease that exponentially approached a steady state level at which the pump current is compensated by the (reverse) leak current due to the membrane conductance. It was shown that there is a linear relation between the fluorescence level and the electric membrane potential, $U .{ }^{9}$ Under the steady state condition the relation holds: $I_{\text {pump }}=I_{\text {leak }}=\lambda_{\text {leak }} U$. Since the leak conductance is a lipid dependent constant, the pump current is proportional to the steady state fluorescence level. To allow a comparison between different experiments, the fluorescence changes were normalized with respect to the initial fluorescence level, $F_{0}(U=$ $0)$, before the addition of ATP,

$$
F_{\text {norm }}(t)=\frac{F(t)-F_{0}}{F_{0}}
$$

where $F_{\text {norm }}(t)$ is the normalized fluorescence amplitude, and $F(t)$ is the measured fluorescence.

The initial slope of the fluorescence change, defined as the derivative of the signal with respect to the time at $t=0$, is directly proportional to the initial enzyme activity. ${ }^{15}$ In short, the initial slope of the electric membrane potential can be defined as the derivative of the time course of the exponentially decreasing membrane potential, $U(t)=U_{\infty}\left(1-\mathrm{e}^{-t / \tau}\right)$, with respect to the time, at $t=0$.

$$
I(t)_{t=0} \propto\left(\frac{\mathrm{d} U}{\mathrm{~d} t}\right)_{t=0}=\left.U_{\infty} \frac{1}{\tau} \mathrm{e}^{-t / \tau}\right|_{t=0}=\frac{U_{\infty}}{\tau}
$$

Considering that the normalized fluorescence level is propor tional to the transmembrane potential build up by the pump, $F_{\text {norm }}=K^{\prime} U$, their corresponding derivatives with respect to time at $t=0$ are also proportional,

$$
\left(\frac{\mathrm{d} U}{\mathrm{~d} t}\right)_{t=0}=\left(K^{\prime}\right)^{-1}\left(\frac{\mathrm{d} F_{\text {norm }}}{\mathrm{d} t}\right)_{t=0}
$$

Taking into account that the maximum amplitude of the normalized fluorescence signal is proportional to the trans membrane potential in the stationary phase, $F_{\max }=K^{\prime} U_{\infty}$, the initial slope of the normalized fluorescence signal is propor tional to the ratio of the maximum amplitude, $F_{\max }$ and the time constant, $\tau$, of the normalized fluorescence signal. All equations taken together, result in

$$
\left(\frac{\mathrm{d} F_{\text {norm }}}{\mathrm{d} t}\right)_{t=0}=\left.K^{*} \frac{F_{\max }}{\tau}\right|_{t=0}=\left.K^{\#} I(t)\right|_{t=0}
$$

where $K^{*}$ is the proportionality factor that depends only on the properties of each specific vesicle preparation, and $K^{\#}=C_{m} K^{*}$, $C_{\mathrm{m}}$ is the membrane capacitance of the vesicle. Therefore, results from the same vesicle preparation can be directly compared, while the proportionality factor may differ between different preparations. The estimation that the initial slope of the fluorescence signal change reflects the initial pump activity is correct under the assumption that the vesicles are of uniform size, and at the initial stage of the experiment when the membrane voltage is still negligible. After longer times of pump activity, the depletion of intravesicular $\mathrm{K}^{+}$becomes a limiting factor, and the membrane voltage may affect the turnover rate.

\section{RESULTS}

Effect of Extravesicular/Cytoplasmic $\mathrm{K}^{+}$Concentration on the Pumping Activity of the KdpFABC Complex. Calibration of the fluorescence responses as a function of the membrane potential were described previously. ${ }^{9}$ It was performed by measuring (normalized) steady state fluorescence signals at different ratios of internal and external $\mathrm{K}^{+}$ concentrations in the presence of valinomycin and calculating the respective Nernst potential. Control experiments with 140 $\mathrm{mM} \mathrm{K}{ }^{+}$on both sides of the membrane showed no significant fluorescence change upon addition of valinomycin, in agree ment with the absence of a membrane potential. A linear relationship between the fluorescence response and the corresponding membrane potential was observed in the range between -40 and $-120 \mathrm{mV}$. The transport activity of the reconstituted $\mathrm{KdpFABC}$ complexes was investigated with respect to different $\mathrm{K}^{+}$concentrations present in the external medium. Vesicles were prepared with $140 \mathrm{mM} \mathrm{K}^{+}$inside at $\mathrm{pH}$ 7.2. The concentration of $\mathrm{K}^{+}$in the standard buffer was varied in the range from 0.14 to $140 \mathrm{mM}$, and the ionic strength of the solution was kept constant by addition of Tris ${ }^{+}$. Activation of the $\mathrm{KdpFABC}$ pump was induced by the addition of $1 \mathrm{mM} \mathrm{Mg}$ ATP $(\mathrm{pH} \approx 7)$, and the respective fluorescence decrease was a result of $\mathrm{K}^{+}$extrusion from the vesicles. The fluorescence decrease (Figure 1, inset) was fitted with a monoexponential function, and the initial slope was calculated as the time derivative at $t \rightarrow 0$ (eq 4). The initial (maximal) fluorescence

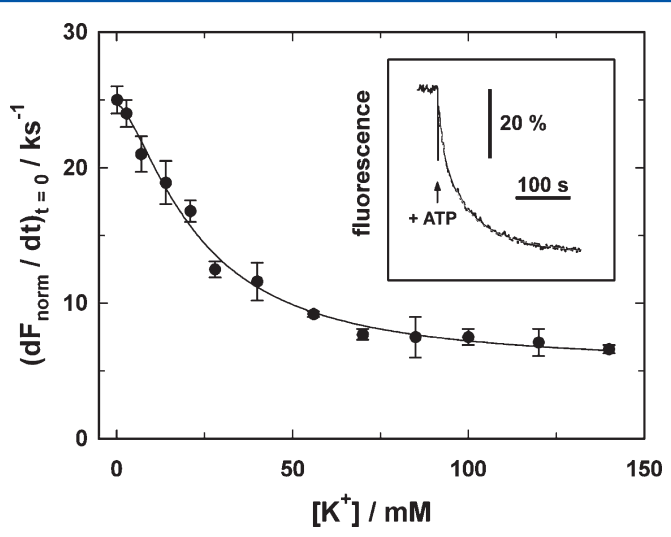

Figure 1. Initial slopes of the ATP induced $\mathrm{DiSC}_{3}(5)$ fluorescence decrease as a function of $\mathrm{K}^{+}$concentration present in the external medium. The initial slope reflects the KdpFABC pump activity. The intravesicular $\mathrm{K}^{+}$concentration was constant $140 \mathrm{mM}$ at $\mathrm{pH}$ 7.2. The concentration dependence was fitted with a Hill function, with a $K_{\mathrm{i}}\left(\mathrm{K}_{\mathrm{ex}}^{+}\right)=23 \pm 2 \mathrm{mM}$ and a Hill coefficient of $n=1.5 \pm 0.2$ (s.e.m.). The inset shows an example of a fluorescence trace of an ATP induced generation of a membrane potential built up across the vesicle membrane. The vesicles were added to standard buffer containing 140 $\mathrm{mM} \mathrm{K} \mathrm{K}^{+}$. Upon addition of $1 \mathrm{mM} \mathrm{MgATP}$ an exponential drop of the fluorescence was observed. The time course was fitted by a single exponential, $F(t)=F_{\max }(1-\exp (-t / \tau))$, with a time constant of $\tau=$ $48.2 \mathrm{~s}$ and a fluorescence amplitude, $F_{\max }=0.35$ (gray line). According to eqs 2 and 3 , this results in an initial slope of the fluorescence decrease, $\left|\mathrm{d} F_{\text {norm }} / \mathrm{d} t\right|=F_{\max } / \tau$, of $0.0072 \mathrm{~s}^{-1}=7.2 \mathrm{ks}^{-1}$. 
decrease per time, reflecting the maximal pump current, was found to be $-6.6 \pm 0.3 \mathrm{~s}^{-1}$ in extravesicular $140 \mathrm{mM} \mathrm{K}$ and 5 $\mathrm{mM} \mathrm{Mg}^{2+}$. The calculated initial slopes were plotted as a function of the external $\mathrm{K}^{+}$concentration (Figure 1). It was observed that the initial pumping activity of the reconstituted $\mathrm{KdpFABC}$ complex decreased with increasing $\mathrm{K}^{+}$concentration of the external medium, indicating an inhibitory effect of the extravesicular (cytoplasmic) potassium concentration. The concentration dependence of the initial slope was fitted with a Hill function, and an inhibition constant, $K_{\mathrm{i}}\left(\mathrm{K}^{+}\right)_{\mathrm{ex}}$ was determined as the $\mathrm{K}^{+}$concentration at which the inhibition of the KdpFABC pumping activity is half maximal. The obtained value was found to be $23 \pm 2 \mathrm{mM}$ with a Hill coefficient of $n=$ $1.5 \pm 0.2$

Effect of Extravesicular $\mathrm{Mg}^{2+}$ Concentrations on the Pumping Activity. In the second set of experiments, the $\mathrm{Mg}^{2+}$ concentration in the external medium was varied. To investigate the effect of magnesium on the pumping activity of the reconstituted $\mathrm{KdpFABC}$, vesicles were prepared as described above. The same buffer $(25 \mathrm{mM}$ imidazole, $1 \mathrm{mM}$ EDTA, $140 \mathrm{mM} \mathrm{K}^{+}, \mathrm{pH}$ 7.2) was used as external medium with different $\mathrm{MgSO}_{4}$ concentrations between 0 and $20 \mathrm{mM}$. The pump activity was induced by addition of $1 \mathrm{mM} \mathrm{Na}_{2}$ ATP ( $\mathrm{pH}$ $\approx 7$ ). In the absence of magnesium, no pump activity was measured as expected. The fluorescence decrease in the presence of respective $\mathrm{Mg}^{2+}$ concentrations was fitted with a monoexponential function, and the pump current represented by the initial slope was determined as a characteristic parameter. The dependence of the initial slope on the free magnesium concentration is shown in Figure 2. The free $\mathrm{Mg}^{2+}$

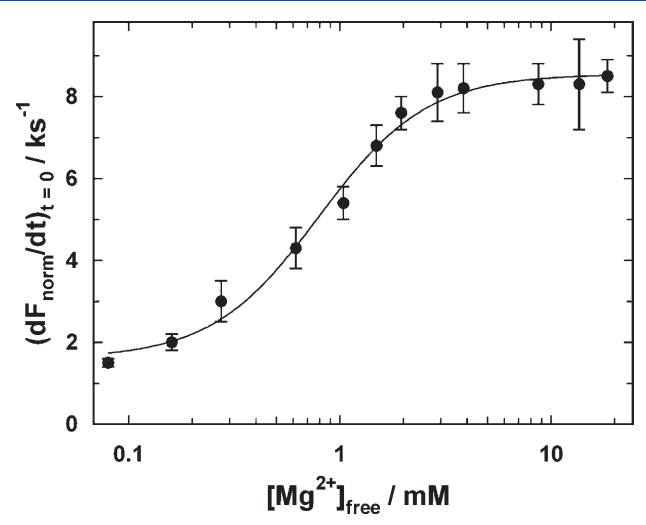

Figure 2. Calculated initial slopes, reflecting the initial KdpFABC pump activity, as a function of external $\mathrm{Mg}^{2+}$ concentration at $\mathrm{pH}$ 7.2. The $\mathrm{K}^{+}$concentration of $140 \mathrm{mM}$ was the same inside and outside of the vesicles. The data were fitted with a Hill function, providing the $K_{1 / 2}\left(\mathrm{Mg}^{2+}\right)$ of $0.8 \pm 0.1 \mathrm{mM}$, and a Hill coefficient, $n$, of $1.7 \pm 0.2$ (s.e.m.).

concentrations were calculated from the total $\mathrm{Mg}^{2+}$ concen tration and the buffer composition using the program winmaxc32 (C. Patton, Stanford University, Palo Alto, CA). Data were fitted with a Hill function, and the corresponding $K_{1 / 2}\left(\mathrm{Mg}^{2+}\right)$ was found to be $0.8 \pm 0.1 \mathrm{mM}$. The Hill coefficient, $n$, of $1.7 \pm 0.2$ indicates binding of more than one $\mathrm{Mg}^{2+}$ ion. The presented results reveal that the pumping activity of the reconstituted $\mathrm{KdpFABC}$ increased with increasing $\mathrm{Mg}^{2+}$ concentration up to $20 \mathrm{mM}$.

Effect of ADP and Inorganic Phosphate on the Pumping Activity. At the beginning of the experiments, the internal and external $\mathrm{K}^{+}$concentration was $140 \mathrm{mM}$ with different aliquots of concentrated stock solutions of $\mathrm{ADP}$ or $\mathrm{P}_{\mathrm{i}}$ added to the external medium. When a stable fluorescence signal was achieved, pump activity was triggered by addition of $1 \mathrm{mM} \mathrm{Mg} \mathrm{ATP}(\mathrm{pH} \approx 7)$, followed by a fluorescence signal decrease to a new steady state state. Corresponding time dependent fluorescence traces of ATP driven $\mathrm{K}^{+}$extrusion at different $\mathrm{ADP}$ concentrations in the external medium are shown in Figure 3. Fluorescence decreases were fitted with a

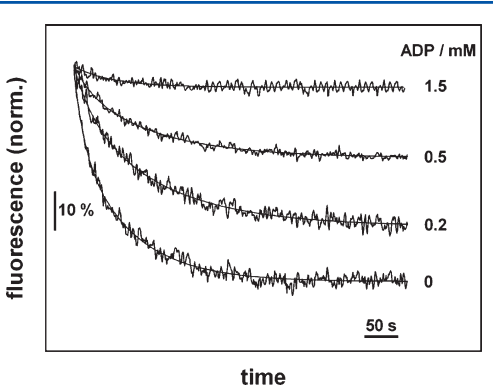

Figure 3. ATP induced $\mathrm{K}^{+}$transport at different ADP concentrations in the external medium. The $\mathrm{K}^{+}$concentration was $140 \mathrm{mM}$ (inside an outside of the vesicles) at $\mathrm{pH} 7.2$. The external buffer contained $5 \mathrm{mM}$ $\mathrm{MgSO}_{4}$. Addition of ADP prior ATP addition did not produce a significant $\mathrm{DiSC}_{3}(5)$ fluorescence change. The maximal fluorescence decrease shows a clear decrease with increasing ADP concentration. The lines through the fluorescence traces are fits with a monoexponential function.

single exponential function, and initial slopes were plotted against the corresponding ADP or $\mathrm{P}_{\mathrm{i}}$ concentrations. Data were fitted with a Michaelis-Menten function, and calculated half maximal inhibiting concentrations of ADP and $\mathrm{P}_{\mathrm{i}}$ were $K_{\mathrm{i}}=151$ $\pm 18 \mu \mathrm{M}$ and $K_{\mathrm{i}}=268 \pm 75 \mu \mathrm{M}$, respectively (Figure 4). The amplitudes of the fluorescence responses upon ATP activation decreased with increasing both $\mathrm{ADP}$ and $\mathrm{P}_{\mathrm{i}}$ concentrations (Figure 3, shown for ADP). In comparison with the results

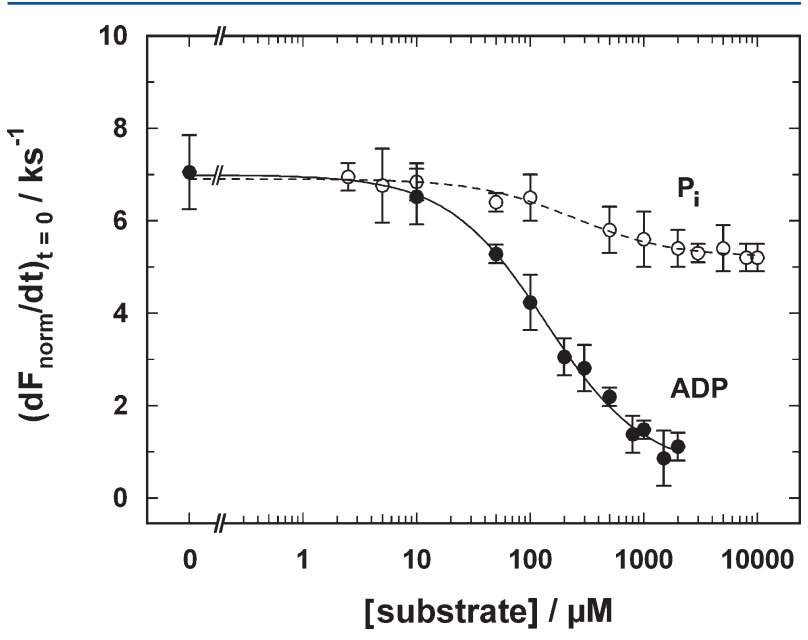

Figure 4. Initial slope, $\left[\left(\mathrm{dF}_{\text {norm }} / \mathrm{d} t\right)_{t_{0}}\right]_{\text {max }}$, of the $\operatorname{DiSC}_{3}(5)$ fluorescence as a function of ADP (filled circles) and $P_{i}$ (open circles). The ATP concentration was $1 \mathrm{mM}$, whereas internal and external $\mathrm{K}^{+}$concentration was $140 \mathrm{mM}$. Data were fitted with a Hill function, with $K_{\mathrm{i}}(\mathrm{ADP})$ of $151 \pm 18 \mu \mathrm{M}$ and a Hill coefficient of 0.88 \pm 0.09 , and $K_{\mathrm{i}}\left(\mathrm{P}_{\mathrm{i}}\right)$ of $268 \pm 75 \mu \mathrm{M}$ and a Hill coefficient of $0.66 \pm$ 0.13 (s.e.m.). 
obtained for the Na,K ATPase, it was found that the kinetics of inhibition seems to be similar for $\mathrm{ADP}$, because the half maximal inhibitory concentrations are at the same order of magnitude. On the other hand, inhibition of the $\mathrm{Na}$,K ATPase by inorganic phosphate was found to be only weak, whereas a much stronger inhibitory effect was observed for the reconstituted $\mathrm{KdpFABC}$ complex.

Inhibition by $\boldsymbol{o}$-Vanadate. The first set of experiments consisted of the determination of the enzyme activity by the malachite green ATPase assay of $\beta$ DDM solubilized enzyme in the presence of different $o$ vanadate concentrations between 0 and $1 \mathrm{mM}$. The ATP concentration was kept constant at saturating $667 \mu \mathrm{M}$. For each $o$ vanadate concentration, three independent measurements were performed, and the average enzyme activity was calculated. The $o$ vanadate concentration dependence was fitted with a Hill function yielding a half inhibitory concentration, $K_{\mathrm{i}}$, of $1.03 \pm 0.08 \mu \mathrm{M}$, and a Hill coefficient of $1.5 \pm 0.1$ (data not shown). At $1 \mathrm{mM} o$ vanadate, the enzyme activity was reduced to $0.02 \mu \mathrm{mol}$ of $\mathrm{P}_{\mathrm{i}}$ (mg of protein $)^{-1} \mathrm{~min}^{-1}$, which corresponds to $\sim 4 \%$ of the initial value of $0.53 \mu \mathrm{mol}$ of $\mathrm{P}_{\mathrm{i}}(\mathrm{mg} \text { of protein })^{-1} \mathrm{~min}^{-1}$.

The inhibitory effect of the $o$ vanadate was investigated also with $\mathrm{KdpFABC}$ reconstituted in vesicles. The malachite green assay was performed with vesicles in the absence of detergent as described above. The concentration of $o$ vanadate was varied between 0 and $5 \mathrm{mM}$, while the ATP concentration was kept constant at $667 \mu \mathrm{M}$. The experiments were performed in triplicate for each $o$ vanadate concentration, and the average ATPase activity was calculated (Figure 5A). In the absence of $o$ vanadate, the ATPase activity of the reconstituted KdpFABC used in this series of experiments was found to be $0.175 \pm$ $0.002 \mu \mathrm{mol}$ of $\mathrm{P}_{\mathrm{i}}$ (mg of protein $)^{-1} \mathrm{~min}^{-1}$ in buffer containing $140 \mathrm{mM} \mathrm{K}^{+}$and $5 \mathrm{mM} \mathrm{Mg}{ }^{2+}$. The $o$ vanadate concentration dependence was fitted with the Michaelis-Menten function, with a $K_{\mathrm{i}}$ of $62 \pm 7 \mu \mathrm{M}$. The enzyme activity was reduced to $0.065 \pm 0.002 \mu \mathrm{mol}$ of $\mathrm{P}_{\mathrm{i}}(\mathrm{mg} \text { of protein })^{-1} \mathrm{~min}^{-1}$ at $5 \mathrm{mM} o$ vanadate. This means that about $37 \%$ of the enzyme activity could not be inhibited by $5 \mathrm{mM} o$ vanadate in the reconstituted preparation.

Another approach to investigate the inhibitory effect of $o$ vanadate was carried out by measuring the $\mathrm{K}^{+}$transport out of the vesicles with $\operatorname{DiSC}_{3}(5)$ in the presence of various concentration of the inhibitor. Vesicles were formed and studied in the presence of $70 \mathrm{mM} \mathrm{K}_{2} \mathrm{SO}_{4}$ (inside and outside). $\mathrm{K}^{+}$export was triggered by addition of $1 \mathrm{mM} \mathrm{Mg} \mathrm{ATP}(\mathrm{pH} \approx$ 7). After a stable fluorescence signal was obtained, correspond ing to the maximal negative membrane potential, aliquots of $o$ vanadate stock solution were added, resulting in a fluorescence signal increase to a new steady state. Because of the partial inhibition of the pump activity, a lower steady state membrane potential was maintained that met the condition that pump and leak current compensated each other again. The amplitudes of the steady state fluorescence levels were plotted against the respective $o$ vanadate concentrations (Figure 5B). The data could be fitted by a Hill function with a half maximal inhibition constant of $K_{\mathrm{i}}=58 \pm 4 \mu \mathrm{M}$ and a Hill coefficient $n=0.47 \pm$ 0.11 . At $3 \mathrm{mM} o$ vanadate, the remaining steady state fluorescence was reduced to $\sim 32 \%$ of the level in absence of the inhibitor. This number agrees with the fraction of uninhibited KdpFABC complexes obtained from the activity measurements.

Temperature Dependence of the KdpFABC Pumping Activity. To gain insight into the energetics of the KdpFABC
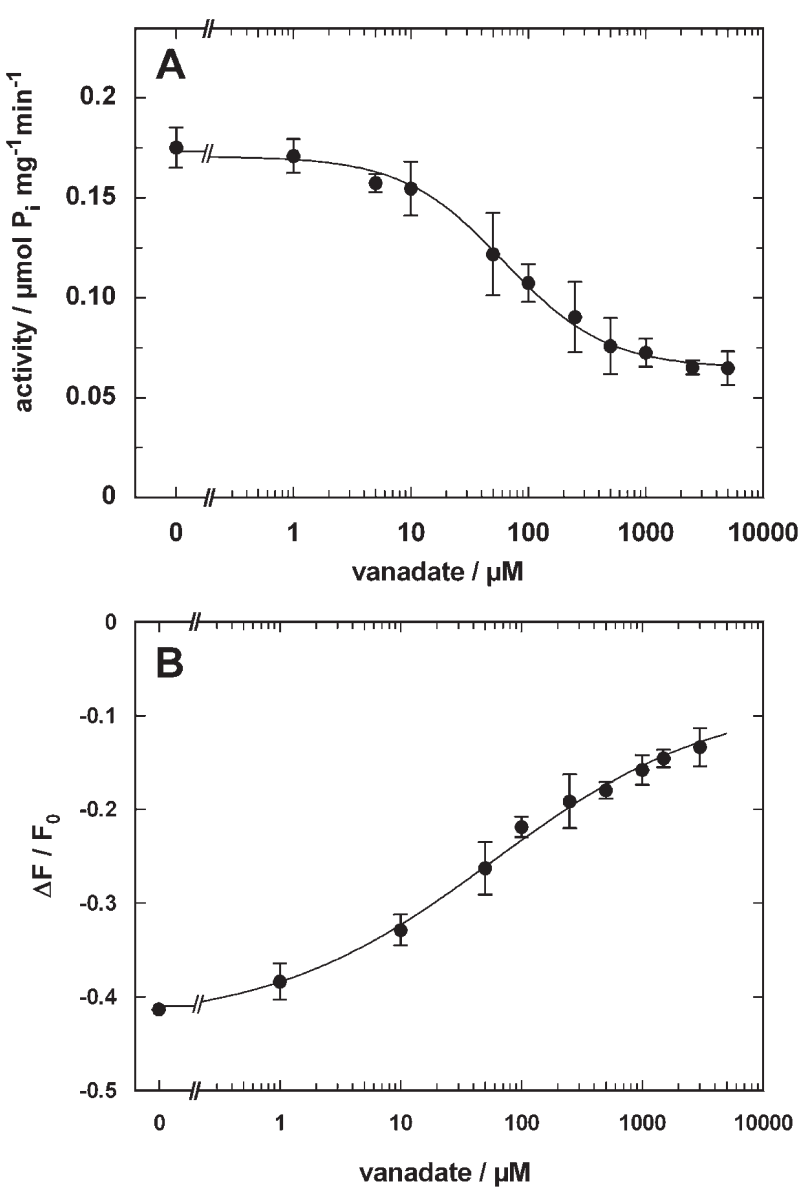

Figure 5. Inhibition of the ATPase activity of reconstituted KdpFABC into vesicles by $o$ vanadate. (A) The malachite green assay performed at different $o$ vanadate concentrations. The data were fitted with a Hill function, and the respective half maximal inhibitory concentration $K_{\mathrm{i}}$ was $62 \pm 7 \mu \mathrm{M}$. (B) $\operatorname{DiSC}_{3}$ (5) fluorescence increase upon addition $o$ vanadate in small aliquots. The data were fitted with a Hill function and a $K_{\mathrm{i}}$ of $58 \pm 4 \mu \mathrm{M}$ was determined.

complex, the temperature dependence of its enzymatic and transport functions was determined. The malachite green assay was performed with the $\beta$ DDM solubilized KdpFABC complex at various temperatures to determine the activation energy under turnover conditions and nonlimiting substrate conditions. Aliquots were incubated for $30 \mathrm{~min}$ at temperatures between 6 and $40{ }^{\circ} \mathrm{C}$ in buffer containing $50 \mathrm{mM}$ Tris $\mathrm{HCl}, 3.3$ $\mathrm{mM} \mathrm{KCl}, 2 \mathrm{mM} \mathrm{MgCl}, 0.67 \mathrm{mM} \mathrm{Na}_{2}$ ATP at $\mathrm{pH}$ 7.8. At higher temperatures $\left(>40{ }^{\circ} \mathrm{C}\right)$, the ATPase activity strongly decreased, probably due to denaturation of the KdpFABC complex. For each temperature, three independent measure ments were averaged (data not shown). Presenting the enzyme activities as an Arrhenius plot allowed the determination of the activation energy, $E_{\mathrm{a}}=55 \pm 1 \mathrm{~kJ} / \mathrm{mol}$, which is in good agreement with recent experiments.

To determine the activation energy of ATP driven $\mathrm{K}^{+}$ transport across the membrane, experiments with reconstituted vesicles were performed, and the initial pump current was calculated from the $\operatorname{DiSC}_{3}(5)$ fluorescence decrease. Vesicles were prepared in buffer of $25 \mathrm{mM}$ imidazole, $1 \mathrm{mM}$ EDTA, 5 $\mathrm{mM} \mathrm{MgSO}$, and $70 \mathrm{mM} \mathrm{K}_{2} \mathrm{SO}_{4}$ at $\mathrm{pH}$ 7.2. Experiments were performed at various temperatures between 12 and $29^{\circ} \mathrm{C}$, three 
at each temperature. The ATP induced fluorescence decrease was fitted with a monoexponential function, the initial slope was calculated using eq 4 , and the average from the three experiments was determined. According to eq 4, the initial slope of the fluorescence decrease is proportional to the rate constant of the rate limiting reaction step of the pump cycle, $k$ $=1 / \tau$, and therefore, may be represented as an Arrhenius plot (Figure 6). The activation energy calculated from the linear

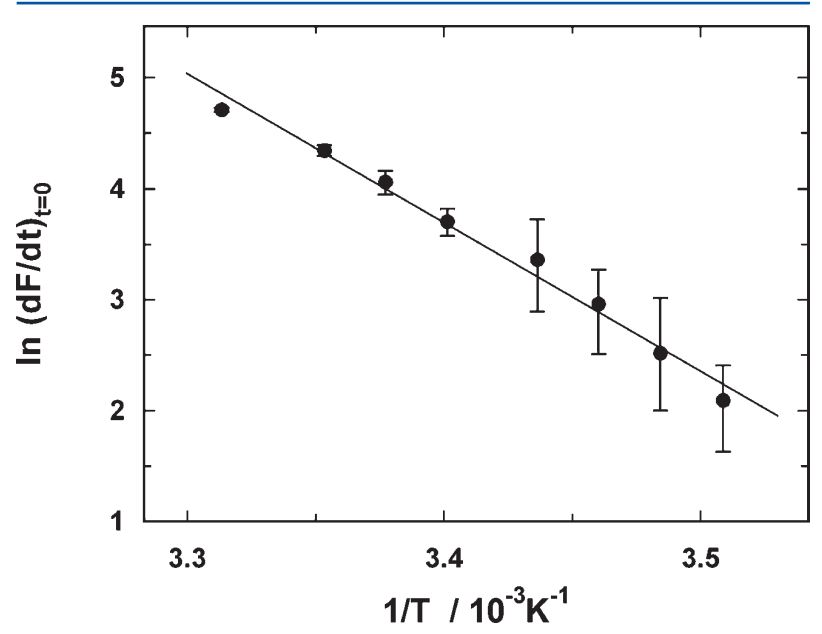

Figure 6. Arrhenius plot of the $\mathrm{K}^{+}$pumping activity of the KdpFABC complex reconstituted in $E$. coli lipid vesicles. The initial pump current is directly proportional to the detected $\operatorname{DiSC}_{3}(5)$ fluorescence decrease, $(\mathrm{d} F / \mathrm{d} t)_{t 0}$. The experiments were performed in the temperature range between 12 and $29{ }^{\circ} \mathrm{C}$. From the regression line, an activation energy of $111 \pm 5 \mathrm{~kJ} / \mathrm{mol}$ was calculated.

slope was $111 \pm 5 \mathrm{~kJ} / \mathrm{mol}$. The 2 fold higher activation energy indicates a significant difference in the rate limiting step when compared to the value obtained from the DDM solubilized enzyme.

\section{DISCUSSION}

To obtain more detailed functional properties of the KdpFABC complex, the $\mathrm{K}^{+}$pump was reconstituted in E. coli lipid vesicles. The advantage of this approach is that on the one hand the protein complex is embedded in a lipid bilayer formed with a lipid mixture isolated from its native host organism. On the other hand, reconstitution allows the separation of substrate enzyme interactions for both sides of the membrane. The disadvantage of vesicle experiments is that the transport activity of the ion pump can be detected only by the amount of ions transferred across the membrane. Individual reaction steps of the pump cycle cannot be resolved directly. This restriction limits the functional details that may be obtained in experiments with vesicles. In the presented experiments, the fluorescence dye $\operatorname{DiSC}_{3}(5)$ was used as a membrane voltage sensor. It was applied already previously to monitor the ion translocating activity of KdpFABC., 13,16 As explained above, the slope of the initial fluorescence decrease upon ATP addition is proportional to the pump current, and this method allows a direct comparison of the substrate dependence of the pump activity in experiments from the same vesicle preparation. ${ }^{9}$ The KdpFABC complexes become inserted into the membrane in either direction during the reconstitution procedure. This fact is, however, without consequences for the experiments performed since ATP is required for activity and was added to the external medium and does not diffuse through the vesicle membrane. Therefore, only inside out oriented ATPases contributed to the detected transport activity. This assay was used to study the effect and concentration dependence of those substrates that interact with the KdpFABC complex from the cytoplasmic side.

Cytoplasmic $\mathrm{K}^{+}$-Concentration Dependence. When the $\mathrm{K}^{+}$concentration dependence of the pump current was studied in vesicles, an inhibitory effect of $\mathrm{K}^{+}$was detected (Figure 1) with a $K_{\mathrm{i}}$ of $23 \mathrm{mM}$. During the physiological function of the pump, potassium ions are transported into the cytoplasm. They have to be released at the cytoplasmic side of the protein. ${ }^{17,18}$ In terms of the Post-Albers scheme of the KdpFABC protein, ${ }^{6,9}$ this reaction step is denoted by $\mathrm{K}_{2} \mathrm{E}_{1} \leftrightarrow \mathrm{E}_{1}+2 \mathrm{~K}^{+}$. Therefore, $K_{\mathrm{i}}$ may be interpreted as an apparent $K_{1 / 2}$ value of the reverse reaction, $\mathrm{K}^{+}$binding to the $\mathrm{E}_{1}$ conformation. At enhanced $\mathrm{K}^{+}$concentrations, the equilibrium of this reaction will be shifted to the left side by a process called $\mathrm{K}^{+}$back binding. Consequently, the flow through subsequent reaction steps and the pump current are reduced. In E. coli the cytoplasmic $\mathrm{K}^{+}$concentration is on the order of $180 \mathrm{mM}$ under physiological conditions; ${ }^{19}$ therefore, only $\sim 10 \%$ of the pumps in the $\mathrm{E}_{1}$ conformation are free of $\mathrm{K}^{+}$and available for progress through the pump cycle, i.e., phosphorylation by ATP as next step. This indicates that in E. coli the cytoplasmic $\mathrm{K}^{+}$ concentration has an inhibitory effect on the KdpFABC complex and that the pump does not gain its maximal turnover rate even at physiological $\mathrm{Mg}^{2+}$ concentrations. According to Figure 1, the pump current at $140 \mathrm{mM} \mathrm{K}^{+}$is about $25 \%$ of the maximal value. When the ion binding sites are accessible from the extracellular side in the $\mathrm{PE}_{2}$ conformation, the half saturating $\mathrm{K}^{+}$concentration was found to be on the order of 2$10 \mu \mathrm{M}^{9,11,20}$ When compared to $\mathrm{K}^{+}$back binding in the $\mathrm{E}_{1}$ conformation, the effective affinity of the binding sites changes by a factor of more than 2000 between both principal conformations of the ion pump.

Cytoplasmic $\mathrm{Mg}^{2+}$-Concentration Dependence. $\mathrm{Mg}^{2+}$ ions are an essential cofactor for KdpFABC phosphorylation, needed to form the enzymatically active MgATP complex as in the case of other P type ATPases. ${ }^{12,21}$ Correspondingly, no ion transport was observed in the absence of $\mathrm{Mg}^{2+}$. Taking into account a dissociation constant of the MgATP complex of 0.1 $\mathrm{mM}$, the concentration of MgATP is saturating $(>0.4 \mathrm{mM})$ in the $\mathrm{Mg}^{2+}$ concentration range covered by the experiments $(>0.5 \mathrm{mM})$ and in the presence of $1 \mathrm{mM}$ ATP. Accordingly, the increase of pump activity by a factor of $\sim 6$ between $0.5 \mathrm{mM}$ and $20 \mathrm{mM} \mathrm{Mg}^{2+}$ has to be assigned to a different interaction of $\mathrm{Mg}^{2+}$ with the protein. High affinity $\mathrm{K}^{+}$binding in the $\mathrm{P} \mathrm{E}_{2}$ conformation has also been found to be affected by $\mathrm{Mg}^{2+}$, and the observed effect could be explained by the Gouy-Chapman effect at the entrance of the extracellular access channel to the ion binding sites. ${ }^{9}$ Magnesium ions adsorb to negatively charged lipid head groups or amino acid side chains in the proximity of the access channel, and thus reduce locally the $\mathrm{K}^{+}$ concentration, which generates in turn an apparently lower binding affinity for $\mathrm{K}^{+}$. The increase of the pump current with increased $\mathrm{Mg}^{2+}$ concentrations on the cytoplasmic side (Figure 2) may be explained accordingly. Binding of $\mathrm{Mg}^{2+}$ close to the cytoplasmic access channel generates a Gouy-Chapman effect that reduces the local $\mathrm{K}^{+}$concentration, and thus $\mathrm{K}^{+}$back binding. The determined Hill coefficient on the order of 2 indicates the contribution of more than one $\mathrm{Mg}^{2+}$ ion, and at 5 $\mathrm{mM} \mathrm{Mg}{ }^{2+}$ present in the buffer almost all $\mathrm{Mg}^{2+}$ binding sites 
are occupied. A rough estimate based on the Gouy-Chapman theory, on the assumption that two $\mathrm{Mg}^{2+}$ ions are located at a distance of $\sim 4 \AA$ from the entrance, results in a reduction of the local $\mathrm{K}^{+}$concentration from $140 \mathrm{mM}$ to $5 \mathrm{mM}$, a value where $\mathrm{K}^{+}$back binding is less strong. In this way, $\mathrm{Mg}^{2+}$ ions bound close to the entrance of the access channel can significantly reduce $\mathrm{K}^{+}$back binding under physiological $\mathrm{Mg}^{2+}$ concen trations and enable a more effective pump process (Figure 2). However, specific $\mathrm{Mg}^{2+}$ sites on the cytoplasmic side of the KdpA subunit have not been identified so far. The half saturating constant of $1.73 \mathrm{mM}$ obtained for $\mathrm{Mg}^{2+}$ influence on the KdpFABC complex is almost three times higher than the value reported in the case of the Na,K ATPase. ${ }^{22}$

Nucleotide-Concentration Dependence. Both products of the ATP hydrolysis, ADP and $\mathrm{P}_{\mathrm{i}}$, were shown to have an inhibitory effect on the enzyme activity ${ }^{12}$ and the pump current (Figures 3 \& 4). This phenomenon was also observed with other P type ATPases, e.g., the Na,K ATPase. ${ }^{23-25}$ The inhibitory effect of ADP was explained by the reversal of the phosphorylation reaction, $\mathrm{E}_{1} \mathrm{ATP} \leftrightarrow \mathrm{E}_{1} \mathrm{P}+\mathrm{ADP}$. With increasing $\mathrm{ADP}$ concentrations, the reaction equilibrium is shifted to the left, and the reaction flow through this partial reaction of the pump cycle becomes rate limiting. The inhibitory constant, $K_{\mathrm{j}}$ of $151 \mu \mathrm{M}$ is in agreement with respective published data for the Na,K ATPase. ${ }^{25}$ Correspond ingly, the inhibition of the pump current by inorganic phosphate is explained in terms of back door phosphorylation, $\mathrm{E}_{2}\left(\mathrm{~K}_{2}\right)+\mathrm{P}_{\mathrm{i}} \rightarrow \mathrm{P} \mathrm{E}_{2} \mathrm{~K}_{2}$, which is the reversal of the dephosphorylation step in the Post-Albers scheme. This process was investigated in great detail for the $\mathrm{Na}, \mathrm{K}$ ATPase. ${ }^{25,26}$ Under comparable experimental conditions, i.e., in the presence of saturating ATP concentrations, the half maximal inhibiting $\mathrm{P}_{\mathrm{i}}$ concentration was found to be $\sim 14 \mathrm{mM}$ for the Na,K ATPase, while the KdpFABC complex showed an approximately 50 fold higher sensitivity $\left(K_{\mathrm{i}}=268 \mu \mathrm{M}\right)$. To find an explanation for this difference, one can consult experiments in which back door phosphorylation of the $\mathrm{Na}, \mathrm{K}$ ATPase was measured in the absence of ATP. Under this condition, the half saturating $\mathrm{P}_{\mathrm{i}}$ concentration was $23 \mu \mathrm{M}^{26}$ This observation indicates that in the applicable reaction sequence of the pump cycle, P $E_{2} K_{2} \leftrightarrow E_{2}\left(K_{2}\right) \leftrightarrow E_{2}\left(K_{2}\right)$ ATP, the presence of ATP is able to drain the $\mathrm{E}_{2}\left(\mathrm{~K}_{2}\right)$ state of the pump, when it binds in the $\mathrm{E}_{2}$ conformation to the so called low affinity binding sites, and thus, an apparently lower binding affinity for $P_{i}$ is measured. According to this consideration, the detected high $\mathrm{P}_{\mathrm{i}}$ affinity of the KdpFABC complex may be explained by a lower binding affinity for ATP to the $\mathrm{E}_{2}\left(\mathrm{~K}_{2}\right)$ state than in the case of the $\mathrm{Na}, \mathrm{K}$ ATPase. A conspicuous difference between the inhibiting action of $\mathrm{ADP}$ and $\mathrm{P}_{\mathrm{i}}$ is obvious at the limit of high concentrations. ADP was able to abolish the pump current almost completely, while $\mathrm{P}_{\mathrm{i}}$ reduced the pump current only by $\sim 20 \%$.

o-Vanadate Inhibition. Many ATPases and especially P type ATPases are inhibited by $o$ vanadate, which acts as a transition state analogue of phosphate. $o$ Vanadate binds in the presence of $\mathrm{Mg}^{2+}$ to the dephosphorylated $\mathrm{E}_{2}$ state with a high affinity in the micromolar concentration range. ${ }^{27}$ The inhibitory effect was also shown for the KdpFABC complex. ${ }^{11-13,28}$ While the inhibition constant obtained from the enzyme activity, $K_{\mathrm{i}}$, was $1 \mu \mathrm{M}$ in the case of the solubilized enzyme complex, it was $62 \mu \mathrm{M}$ for the reconstituted $\mathrm{KdpFABC}$ complex (Figure 5A). When the effect of $o$ vanadate on the pump current across the vesicle membrane was determined, a comparable $K_{\mathrm{i}}$ of $58 \mu \mathrm{M}$ was found under the same conditions. In the case of the solubilized $\mathrm{KdpFABC}$ complex, $93 \%$ of the enzyme activity was inhibited by $1 \mathrm{mM} o$ vanadate, while in the case of the reconstituted enzyme only $\sim 65 \%$ could be inhibited with $5 \mathrm{mM}$ $o$ vanadate. Because the data could be fit satisfactorily by a Michaelis-Menten approach, the remaining enzyme activity seems to be inert against inhibition, and this indicates a severe modification of a fraction of the $\mathrm{KdpFABC}$ complexes with respect to its interaction with $o$ vanadate. This significantly different effect of the inhibitor on both the solubilized and reconstituted form may have two different reasons: (1) The environment of the complex is different; in one case, it is surrounded by a narrow and strongly curved annulus of $\beta$ DDM molecules and lipids. In the other case, the complex is embedded in a lipid bilayer of $E$. coli lipids with a very low detergent concentration. (2) The $\mathrm{K}^{+}$concentration is saturating in both cases, but in the experiments with solubilized enzyme it is significantly lower $(3.3 \mathrm{mM})$ than with vesicles $(140 \mathrm{mM})$. The half saturating $\mathrm{K}^{+}$concentration on the cytoplasmic side of the ion pump was determined to be $23 \mathrm{mM}$. The $K_{\mathrm{i}}$ value of $o$ vanadate obtained for the complex solubilized in $\beta \mathrm{DDM}$ is in agreement with the value of $1.5 \mu \mathrm{M}$ obtained for complexes solubilized in a different detergent, Aminoxide WS 35. ${ }^{11}$ Investigations of the $K_{\mathrm{i}}$ value in native cells are not available. From studies with other $\mathrm{P}$ type ATPases, it is known that $o$ vanadate is a potent inhibitor with $K_{\mathrm{i}}$ values $<10 \mu \mathrm{M}^{29-31}$ Therefore, it is reasonable to propose that the values of $K_{\mathrm{i}}$ obtained from the vesicle preparations were distorted by the experimental conditions.

The reduced affinity for $o$ vanadate became visible in both sets of experiments with the reconstituted KdpFABC complex, in the enzyme activity as well as in the stationary membrane potential during pump activity. It has to be mentioned, however, that the stationary membrane potential is an indirect approach because the observed effect is coupled to the voltage dependent leak currents through the membrane. The influence of other experimental conditions is reflected in the reduced Hill coefficient of $\sim 0.5$.

The high $\mathrm{K}^{+}$concentration in the vesicle experiments may be excluded as a cause of the reduced $K_{\mathrm{i}}$ value because $140 \mathrm{mM} \mathrm{K}^{+}$ would promote $\mathrm{K}^{+}$back binding (Figure 1), and thus increase the population of the $E_{2}\left(K_{2}\right)$ state that would in turn enhance $o$ vanadate binding, and apparently, increase binding of the inhibitor. This is contrary to the experimental finding.

At the present state, the reduced capacity of $o$ vanadate to inhibit the enzymatic and transport activity in reconstituted vesicles is a promising hint at the affected mechanism. At $1 \mathrm{mM}$ $o$ vanadate only $\sim 63 \%$ of the inside out oriented $\mathrm{KdpFABC}$ complex is inhibited (compared to $>90 \%$ of the solubilized enzyme). This observation indicates that embedding of the complex into the lipid bilayer may modify the moiety to which the inhibitor has to bind such that it becomes much less attractive in a way (or is even disabled). This hypothesis would be supported by the observation that in the presence of even 10 $\mathrm{mM} \mathrm{P} \mathrm{P}_{\mathrm{i}}$, which binds in the same state to the same site, the pump current is also reduced not more than $24 \%$; in contrast, 2 $\mathrm{mM} \mathrm{ADP}$ that binds to the $\mathrm{P}_{1}$ state reduces the pump current more than $85 \%$ (Figure 4 ). To reveal the true origin of this phenomenon, an elaborate study of the lipid dependence on this effect has to be conducted.

Activation Energy of the Rate-Limiting Steps. The activation energy of the KdpFABC complex reconstituted was determined from the enzyme activity and the initial pump 
current through the vesicle membrane. In both approaches, the KdpFABC complex works under turnover conditions. Never theless, the activation energy was higher by a factor of 2 in the case of the pump current $(111 \mathrm{~kJ} / \mathrm{mol}$ vs $55 \mathrm{~kJ} / \mathrm{mol})$. To determine the origin of this significant effect, the differences in both assays have to be considered as in the case of the $o$ vanadate inhibition. The activation energy is a characteristic parameter of the rate limiting reaction step in the reaction sequence observed in the experiment. In both cases, the enzymes work under turnover conditions, and in previous investigations it was found that the rate limiting reaction steps of the solubilized complex are the conformation transitions with activation energies of up to $61 \mathrm{~kJ} / \mathrm{mol}$ under the various conditions. ${ }^{6}$ The large difference observed between the solubilized and reconstituted complex have to be caused, therefore, by either a different conformation transition that comes into play upon reconstitution or by the same transition whose activation energy has been doubled in the lipid bilayer environment.

A direct comparison of the enzyme activity of the solubilized and reconstituted $\mathrm{KdpFABC}$ complex is impossible since the precise distribution of the inside and right side out oriented proteins is unknown. Assuming an equal distribution of the pumps in the vesicle membrane, the turnover number of the reconstituted pumps would be $20 \%$ higher at $37^{\circ} \mathrm{C}$ as can be calculated from the data in the absence of vanadate (see above). At $\sim 24{ }^{\circ} \mathrm{C}$, however, the turnover rate would be slower by a factor of 2 on the basis of the determined activation energies.

The same possibly relevant differences between both preparations have to be discussed as in the case of the $o$ vanadate inhibition. First, the amount of detergent molecules encasing the membrane domain of the KdpFABC complex was high for the solubilized and low for the reconstituted protein. Second, the experiments with the solubilized enzyme were performed in the presence of $3.3 \mathrm{mM} \mathrm{K}^{+}$and $2 \mathrm{mM} \mathrm{Mg}^{2+}, \mathrm{pH}$ 7.8 , while the pump current was studied in the presence of 140 $\mathrm{mM} \mathrm{K}^{+}$and $5 \mathrm{mM} \mathrm{Mg}^{2+}, \mathrm{pH}$ 7.2. On the basis of the magnitude of the activation energy, a modification of ion binding and release reactions may be excluded as origin of the effects because changes of $\sim 55 \mathrm{~kJ} / \mathrm{mol}$ require major changes in the reaction mechanism. To propose a modified interaction between the $\mathrm{KdpA}$ and $\mathrm{KdpB}$ subunit is a reasonable working hypothesis. However, similar to the analysis of the $o$ vanadate effects, further detailed studies on the lipid dependence of activation energy are required to gain further mechanistic insights.

\section{CONCLUSIONS}

The investigation of the $\mathrm{KdpFABC}$ complex reconstituted in lipid vesicles allowed the analysis of substrate interactions specifically with binding sites on the cytoplasmic side of the ion pump. In the $\mathrm{E}_{1}$ conformation the ion binding sites, assumed to be located in the KdpA subunit, are accessible from the cytoplasm and have a $\mathrm{K}^{+}$binding affinity about 2000 fold lower than when accessible from the opposite side of the membrane. Nevertheless, significant back binding of $\mathrm{K}^{+}$would occur and effectively reduce $\mathrm{K}^{+}$transport by the pump at physiological $\mathrm{K}^{+}$ concentrations in the cytosol $(>100 \mathrm{mM})$. This effect is, however, counteracted by binding of $\mathrm{Mg}^{2+}$ ions close to the terminus of the cytoplasmic access channel, which reduces significantly the local $\mathrm{K}^{+}$concentration due to the GouyChapman effect. Accordingly, binding of $\mathrm{Mg}^{2+}$ avoids the necessity of an even larger shift of the binding affinity of the $\mathrm{K}^{+}$ sites and ensures that $\mathrm{K}^{+}$release from their binding sites is less affected by back binding under physiological conditions.

A second class of substrate interaction occurs at the cytoplasmic surface of the $\mathrm{KdpB}$ subunit. Higher concen trations of $\mathrm{ADP}$, as product of the phosphorylation reaction, $\mathrm{E}_{1}$ $+\mathrm{ATP} \leftrightarrow \mathrm{P} \mathrm{E}_{2}+\mathrm{ADP}$, affect this reaction step in the expected manner by reversing this step and reducing the reaction flow appropriately. More complex were the findings with the reconstituted complex concerning the dephosphorylation of the enzyme, $\mathrm{P} \mathrm{E}_{2} \mathrm{~K}_{2} \rightarrow \mathrm{E}_{2}\left(\mathrm{~K}_{2}\right)+\mathrm{P}_{\mathrm{i}}$. When this reaction is reversed in a so called backdoor phosphorylation by addition of inorganic phosphate, the pump current could be reduced by only a small fraction. The inhibition by $o$ vanadate that takes place at exactly the same reaction step, in which it replaces phosphate, shows a similar behavior. It seems that the process of binding of phosphate (or its transition state analogue) and the concomitant conformational rearrangement were affected by the environment created by the lipids present in the vesicle membrane. This hypothesis is supported by the recent finding that $\mathrm{K}^{+}$binding affinity and the enzyme activity are also extremely sensitive to the detergent in which the KdpFABC complex was purified. $^{9}$ It was proposed that a so far unidentified component in the mixture of detergents used there was crucial for reproducing best the in vivo properties of the enzyme.

\section{AUTHOR INFORMATION}

\section{Corresponding Author}

*Phone: +49 7531 882253. Fax: +49 7531 883183. E mail: h j. apell@uni konstanz.de.

\section{Present Address}

\#(B.D.) Structural Biology, Max Planck Institute of Biophysics, 60438 Frankfurt am Main, Germany

\section{Funding}

We gratefully acknowledge funding from the Konstanz Research School Chemical Biology, University of Konstanz, Germany, and the University of Konstanz (AFF 4/68).

\section{Notes}

The authors declare no competing financial interest.

\section{ABBREVIATIONS}

$\operatorname{DiSC}_{3}(5)$, dipropylthiadicarbocyanine iodide; $\beta \mathrm{DDM}, n$ dodecyl $\beta$ D maltoside; $\mathrm{C}_{12} \mathrm{E}_{8}$, octaethylene glycol monodo decyl ether

\section{REFERENCES}

(1) Bramkamp, M., Altendorf, K., and Greie, J. C. (2007) Common patterns and unique features of $\mathrm{P}$ type ATPases: a comparative view on the KdpFABC complex from Escherichia coli (Review). Mol. Membr. Biol. 24, 375-386.

(2) Sweadner, K. J., and Donnet, C. (2001) Structural similarities of $\mathrm{Na}, \mathrm{K}$ ATPase and SERCA, the $\mathrm{Ca}^{2+}$ ATPase of the sarcoplasmic reticulum. Biochem. J. 356, 685-704.

(3) van der Laan, M., Gassel, M., and Altendorf, K. (2002) Characterization of amino acid substitutions in $\mathrm{KdpA}$, the $\mathrm{K}^{+}$binding and translocating subunit of the KdpFABC complex of Escherichia coli. J. Bacteriol. 184, 5491-5494.

(4) Irzik, K., Pfrotzschner, J., Goss, T., Ahnert, F., Haupt, M., and Greie, J. C. (2011) The KdpC subunit of the Escherichia coli $\mathrm{K}^{+}$ transporting KdpB P type ATPase acts as a catalytic chaperone. FEBS J. 278, 3041-3053.

(5) Gassel, M., Mollenkamp, T., Puppe, W., and Altendorf, K. (1999) The $\mathrm{KdpF}$ subunit is part of the $\mathrm{K}^{+}$translocating $\mathrm{Kdp}$ complex of 
Escherichia coli and is responsible for stabilization of the complex in vitro. J. Biol. Chem. 274, 37901-37907.

(6) Damnjanovic, B., and Apell, H. J. (2014) Role of Protons in the Pump Cycle of KdpFABC Investigated by Time Resolved Kinetic Experiments. Biochemistry 53, 3218-3228.

(7) Buurman, E. T., Kim, K. T., and Epstein, W. (1995) Genetic evidence for two sequentially occupied $\mathrm{K}+$ binding sites in the Kdp transport ATPase. J. Biol. Chem. 270, 6678-6685.

(8) Schrader, M., Fendler, K., Bamberg, E., Gassel, M., Epstein, W., Altendorf, K., and Drose, S. (2000) Replacement of glycine 232 by aspartic acid in the KdpA subunit broadens the ion specificity of the $\mathrm{K}(+)$ translocating KdpFABC complex. Biophys. J. 79, 802-813.

(9) Damnjanovic, B., Weber, A., Potschies, M., Greie, J. C., and Apell, H. J. (2013) Mechanistic analysis of the pump cycle of the KdpFABC P type ATPase. Biochemistry 52, 5563-5576.

(10) Robinson, J. D., and Flashner, M. S. (1979) The $\left(\mathrm{Na}^{+}+\mathrm{K}^{+}\right)$ activated ATPase. Enzymatic and transport properties. Biochim. Biophys. Acta 549, 145-176.

(11) Siebers, A., and Altendorf, K. (1988) The $\mathrm{K}^{+}$translocating Kdp ATPase from Escherichia coli. Purification, enzymatic properties and production of complex and subunit specific antisera. Eur. J. Biochem. $178,131-140$

(12) Siebers, A., and Altendorf, K. (1989) Characterization of the phosphorylated intermediate of the $\mathrm{K}^{+}$translocating Kdp ATPase from Escherichia coli. J. Biol. Chem. 264, 5831-5838.

(13) Fendler, K., Drose, S., Altendorf, K., and Bamberg, E. (1996) Electrogenic K+ transport by the Kdp ATPase of Escherichia coli. Biochemistry 35, 8009-8017.

(14) Vagin, O., Denevich, S., Munson, K., and Sachs, G. (2002) SCH28080, a $\mathrm{K}^{+}$competitive inhibitor of the gastric H,K ATPase, binds near the M5-6 luminal loop, preventing $\mathrm{K}^{+}$access to the ion binding domain. Biochemistry 41, 12755-12762.

(15) Cirri, E., Kirchner, C., Becker, S., Katz, A., Karlish, S. J., and Apell, H. J. (2013) Surface charges of the membrane crucially affect regulation of $\mathrm{Na}, \mathrm{K}$ ATPase by phospholemman (FXYD1). J. Membr. Biol. 246, 967-979.

(16) Becker, D., Fendler, K., Altendorf, K., and Greie, J. C. (2007) The conserved dipole in transmembrane helix 5 of $\mathrm{KdpB}$ in the Escherichia coli KdpFABC P type ATPase is crucial for coupling and the electrogenic $\mathrm{K}^{+}$translocation step. Biochemistry 46, 13920-13928.

(17) Laimins, L. A., Rhoads, D. B., Altendorf, K., and Epstein, W. (1978) Identification of the structural proteins of an ATP driven potassium transport system in Escherichia coli. Proc. Natl. Acad. Sci. U. S. A $75,3216-3219$.

(18) Epstein, W. (1992) Kdp, a bacterial P type ATPase whose expression and activity are regulated by turgor pressure. Acta Physiol Scand. Suppl 607, 193-199.

(19) Shabala, L., Bowman, J., Brown, J., Ross, T., McMeekin, T., and Shabala, S. (2009) Ion transport and osmotic adjustment in Escherichia coli in response to ionic and non ionic osmotica. Environ. Microbiol. 11, 137-148.

(20) Rhoads, D. B., Waters, F. B., and Epstein, W. (1976) Cation transport in Escherichia coli. VIII. Potassium transport mutants. J. Gen. Physiol 67, 325-341.

(21) Fukushima, Y., and Post, R. L. (1978) Binding of divalent cation to phopshoenzyme of sodium and potassium transport adenosine Triphosphatase. J. Biol. Chem. 253, 6853-6862.

(22) Apell, H. J., Häring, V., and Roudna, M. (1990) Na,K ATPase in artificial lipid vesicles. Comparison of $\mathrm{Na}, \mathrm{K}$ and $\mathrm{Na}$ only pumping mode. Biochim. Biophys. Acta 1023, 81-90.

(23) Garrahan, P. J., and Glynn, I. M. (1967) The incorporation of inorganic phosphate into adenosine triphosphate by reversal of the sodium pump. J. Physiol. 192, 237-256.

(24) Kennedy, B. G., Lunn, G., and Hoffman, J. F. (1986) Effects of altering the ATP/ADP ratio on pump mediated $\mathrm{Na} / \mathrm{K}$ and $\mathrm{Na} / \mathrm{Na}$ exchanges in resealed human red blood cell ghosts. J. Gen. Physiol. 87, $47-72$.

(25) Apell, H. J., Nelson, M. T., Marcus, M. M., and Läuger, P. (1986) Effects of the ATP, ADP and inorganic phosphate on the transport rate of the $\mathrm{Na}^{+}, \mathrm{K}^{+}$pump. Biochim. Biophys. Acta 857, 105115.

(26) Apell, H. J., Roudna, M., Corrie, J. E., and Trentham, D. R. (1996) Kinetics of the phosphorylation of $\mathrm{Na}, \mathrm{K}$ ATPase by inorganic phosphate detected by a fluorescence method. Biochemistry 35, 10922-10930.

(27) Cantley, L. C., Cantley, L. G., and Josephson, L. (1978) A characterization of vanadate interactions with the $(\mathrm{Na}, \mathrm{K})$ ATPase. J. Biol. Chem. 253, 7361-7368.

(28) Kollmann, R, and Altendorf, K. (1993) ATP driven potassium transport in right side out membrane vesicles via the Kdp system of Escherichia coli. Biochim. Biophys. Acta 1143, 62-66.

(29) Cantley, L. C., Josephson, L., Warner, R., Yanagisawa, M., Lechene, C., and Guidotti, G. (1977) Vanadate is a potent (Na,K) ATPase inhibitor found in ATP derived from muscle. J. Biol. Chem. 252, 7421-7423.

(30) Pick, U. (1982) The interaction of vanadate ions with the Ca ATPase from sarcoplasmic reticulum. J. Biol. Chem. 257, 6111-6119.

(31) Faller, L. D., Rabon, E., and Sachs, G. (1983) Vanadate binding to the gastric $\mathrm{H}, \mathrm{K}$ ATPase and inhibition of the enzyme's catalytic and transport activities. Biochemistry 22, 4676-4685. 